\title{
Isolation and Characterization of Biofilm Forming Multiple Drug Resistance Bacterial Pathogens from the Urinary Catheters
}

\author{
Jeyakumar Balakrishnan', Suganya Kannan ${ }^{1 *}$ and Ambujam Govindasamy² \\ ${ }^{1}$ Central Research Laboratory, Vinayaka Missions, Medical College and Hospital, Vinayaka \\ Mission's Research Foundation (Deemed to be University), Karaikal \\ ${ }^{2}$ Department of General Surgery, -Vinayaka Missions, Medical College and Hospital, Vinayaka \\ Mission Research Foundation (Deemed to be University), Karaikal
}

\section{ABSTRACT}

Lengthy urinary tract catheterization leading to the bacterial colonization of the urinary tract is a significant determinant of colonization through adherence to the catheter surface. The collection of urine and urinary catheter bacterial isolates of 55 patients was shown to be multiple catheter colonisation, while the Escherichia coli isolates were usually contained in high number in the urine. Kirby Bauer disc diffusion system was used to conduct antimicrobial susceptible patterns of the isolated species. Based on the morphological characterization and some specific biochemical reactions of the most resistant, intermediate and sensitive bacteria, the isolates were identified as, Pseudomonas aeruginosa, Staphylococcus aureus, Escherichia coli, Candida albicans, Enterococcus Sps., Staphylococcus epidermidis, Proteus mirabilis, and Klebsiella pneumoniae. Nearly $67 \%$ the isolates were high biofilm producers with strong adherence.

\section{KEY WORDS: URINARY CATHETERS, BIOFILM PRODUCERS, ANTIMICROBIAL SUSCEPTIBLE PATTERNS.}

\section{INTRODUCTION}

Urinary tract infections (UTIs) are severe health distressing complications worldwide. The most common bacterial pathogens involved UTIs in human beings $E$. coli, E. faecalis, K. pneumoniae, S. marcescens, P. aeruginosa, $S$. saprophyticus, S. aureus and Proteus mirabilis. Around $85 \%$ of the population acquired UTIs and $50 \%$ of the hospital acquired UTIs are mainly caused by E.coli. Different factors like age, gender, immunosuppression and urological instruments may affect prevalence of UTIs.

\section{ARTICLE INFORMATION}

Received 26th Oct 2020 Accepted after revision 17th Dec 2020 Print ISSN: 0974-6455 Online ISSN: 2321-4007 CODEN: BBRCBA

Thomson Reuters ISI Web of Science Clarivate Analytics USA and Crossref Indexed Journal

\section{Clarivate
Analytics}

NAAS Journal Score 2020 (4.31)

A Society of Science and Nature Publication,

Bhopal India 2020. All rights reserved.

Online Contents Available at: http//www.bbrc.in/

Doi: $h t t p: / / d x$.doi.org/10.21786/bbrc/13.15/32
Catheter-associated UTIs are one of the most dangerous health risks contributing 34\% of all health care associated infections. The use of antibiotics and spread of antibiotic resistance in clinical settings is a well-recognized problem, but antibiotics and antibiotic resistance as environmental problems and pollutants have largely been overlooked. As a result, the increasing incidence of resistance to a wide range of antibiotic agents by a variety of organisms is a major concern facing modern medicine.

Detection of UTI causing pathogens and resistance of these pathogens to commonly prescribed antibiotics in clinical set ups is essential and helpful in improving the efficacy of empirical treatment. Objective of the present study was to highlight the bacterial etiology of UTIs and determination of resistance pattern of $E$. coli isolates.

Biofilm formation is an important mechanism by which bacteria survive and persist despite antibiotics and host immune responses. Bacterial biofilms are responsible for the failure of many medical devices and are associated 
with many infectious and non-infectious complications 1. Catheter associated urinary tract infections (CAUTI) are among the most commonly reported hospital acquired infections. Bacteria frequently associated with CAUTI include uropathogenic Escherichia coli (UPEC), Enterococcus spp., Klebsiella pneumoniae, Proteus mirabilis (P. mirabilis), Pseudomonas aeruginosa, etc. Intraluminal and extraluminal biofilms, caused by the attachment of bacteria to the catheter, lead to the entry and subsequent persistence of uropathogens in the bladder. Objective of the present study was to highlight the bacterial etiology of UTIs and determination of resistance pattern of biofilm forming pathogenic isolates.

\section{MATERIAL AND METHODS}

Sample collection and Isolation of Bacteria: Urinary catheter samples $(n=55)$ were collected from patients in different wards. The catheter samples were sonicated and centrifuged with sterile phosphate buffered saline. Resultant residues were cultured mainly on blood agar and macConkey's agar by spread plate technique. Bacterial colonies with dissimilar morphology were designated, purified and known by their biochemical profiles.

Multiple drug resistance: Antibiotic sensitivity pattern of all the isolates were evaluated on Muller Hinton agar plates by Kirby-Bauer disc diffusion assay method. Isolates were stated as sensitive or resistant based on the zone of inhibition results after the measures of Clinical Laboratory standards Institute (CLSI).

\section{Biofilm formation on abiotic surfaces}

Glass surfaces: Biofilm formation was also examined in glass test tubes. The biofilms were formed by adding $0.1 \mathrm{~mL}$ of the culture to $5 \mathrm{~mL}$ Brain heart infusion broth $(0.5 \times)$ distributed in glass test tubes. The trial was did in duplicates and the cultures were incubated at $37{ }^{\circ} \mathrm{C}$ for $72 \mathrm{~h}$ in immobile situation. After incubation, the medium was detached, the tubes were eroded with sterile distilled water, air dried and biofilms were analyzed using the crystal violet staining method. Strain of Pseudomonas aeruginosa PA01 were used as control for the biofilm experiments.

Statistical Analysis Assessments of occurrence data were tested using Chi square $(\chi 2)$ test and Fisher's exact test with GraphPad prism (version 6) statistical software.

\section{RESULTS}

From the 55 catheter samples handled, 45 (81\%) swabs produced at least five bacterial isolate and the remaining $10(19 \%)$ swabs did not produce any bacterial progression. Direct gram stain recovered 102 organisms from the catheters in the form of bacilli, cocci or a mixture of the two. On unique media the bacterial isolates were cultivated and the most frequent were observed and serial code numbers were given. Due to the morphological characterization of the most resistant, intermediate and vulnerable bacteria and unique biochemical reactions, isolates have been identified as, Pseudomonas aeruginosa, Staphylococcus aureus, Escherichia coli, Candida albicans, Enterococcus Sps., Staphylococcus epidermidis , Proteus mirabilis , Klebsiella pneumoniae. Out of 102 bacterial isolates from patients, rate of $E$. coli (33.5 \%) isolation was highest followed by Pseudomonas aeruginosa, Staphylococcus aureus and Proteus species, Klebsiella pneumonia (Table 1).

Multiple drug resistance: Of the 102 isolates 63 isolates were multidrug resistant. The consequences of this study designated that some of the isolated bacterial strains (Table 2) are vulnerable to most the verified antibiotics. From the results it was observed that Pseudomonas aeruginosa (the most resistant isolate) was resistance to Cefitriaxone (30 $\mu \mathrm{g})$, Cefotaxime (30 $\mu \mathrm{g})$; Gentamicin (300 $\mu \mathrm{g})$; while, Staphyloccous aureus and Klebsiella pneumoniae (intermediate isolates) showed resistance toward), Cefotaxime (30 $\mu \mathrm{g})$ and Ceftriaxone (30 $\mu \mathrm{g})$, Netilmicin $(300 \mu \mathrm{g})$, respectively.

\begin{tabular}{|l|c|c|}
\hline \multicolumn{3}{|c|}{ Table 1. Microorganisms associated with catheter mediated infection } \\
\hline Microorganisms & $\begin{array}{c}\text { Catheter associated } \\
\text { with colonization (\%) }\end{array}$ & $\begin{array}{c}\text { Catheter associated with } \\
\text { urinary tract infection (\%) }\end{array}$ \\
\hline Pseudomonas aeruginosa & 24.7 & 42.5 \\
\hline Staphylococcus aureus & 12.3 & 22.5 \\
\hline Escherichia coli & 33.6 & Nil \\
\hline Candida albicans & 7.2 & Nil \\
\hline Enterococcus Sps. & 6.5 & 5.17 \\
\hline Staphylococcus epidermidis & 6 & 13.17 \\
\hline Proteus mirabilis & 5.5 & 20 \\
\hline Klebsiella pneumoniae & 4.7 & 7 \\
\hline
\end{tabular}

Biofilm Formation of Isolates: All the isolates have been investigated with ideal biofilm medium and Polystyrene as base, assessed by adhesiveness, pellicle, and clumping.
Though the degree of biofilm diverse inside a species and among dissimilar species, 95\% of the isolates presented at least one type of biofilm formation. P. aeruginosa 
isolates showed the maximum capability to form biofilm and adherence of all tested species. Although almost all $E$. coli isolates exhibit biofilm formation, the median amount of biofilm in this study was lower than for most isolated species (Figure 1).

\begin{tabular}{|c|c|c|c|c|}
\hline \multirow[t]{2}{*}{ Antibiotics } & \multicolumn{4}{|c|}{ Percentage of isolates showing antibiotic resistance } \\
\hline & $\begin{array}{c}\text { Pseudomonas } \\
\text { aeruginosa }\end{array}$ & $\begin{array}{c}\text { Staphylococcus } \\
\text { aureus }\end{array}$ & $\begin{array}{c}\text { Escherichia } \\
\text { coli }\end{array}$ & $\begin{array}{c}\text { Enterococcus } \\
\text { Sps }\end{array}$ \\
\hline Amoxiclav & 32 & 32 & 43 & 80 \\
\hline Cefitriaxone & 94 & 93 & 77 & 82 \\
\hline Imipenem & 55 & NS & 95 & 97 \\
\hline Gentamicin & 61 & NS & 65 & 63 \\
\hline Ceftazidim & 45 & 67 & 81 & 83 \\
\hline Oxacillin & NS & 65 & NS & NS \\
\hline Netilmicin & 87 & 88 & 21 & NS \\
\hline Clindamycin & NS & 76 & NS & NS \\
\hline Vancomycin & NS & 21 & NS & NS \\
\hline Cotrimoxazol & 45 & NS & 32 & 42 \\
\hline Ciprofloxacin & 56 & 83 & 81 & 47 \\
\hline Amikacin & 57 & 62 & 43 & 47 \\
\hline Piperacillin & 32 & 27 & $\mathrm{~N}$ & $\mathrm{~N}$ \\
\hline Piperacillin/tazobactam & 13 & 14 & 43 & 41 \\
\hline Cefotaxim & 55.7 & 67 & 52 & NS \\
\hline
\end{tabular}

Figure 1: Representative images for the biofilm formation by the pathogens on glass surfaces when incubated at $37^{\circ} \mathrm{C}$ with stationary conditions. A - Enterococcus sps. BStaphylococcus aureus, C- Pseudomonas aeruginosa, D- E. coli, E- Pseudomonas aeruginosa PA01
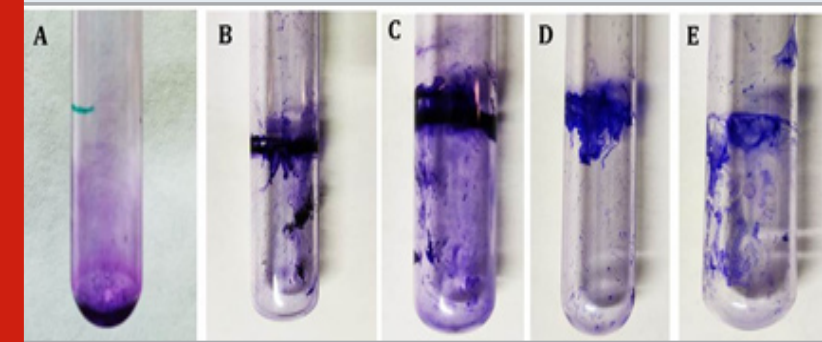

\section{DISCUSSION}

This research explores the prevalence of urinary catheter colonization and infection associated with a bacterial catheter, along with antibiotic resistance trends of isolated bacteria in tertiary care hospital in Indian countries with the quantitative and semi-quantitative techniques. The present study for isolation and identification of organism present in the catheter signifies that in the health care system now the organism which was earlier considered as nonpathogenic are now very much prevalent in a pathogenic form. The elimination of these pathogens is the highest need, as they will lead to an aggravation of already occurring diseases. In certain cases the capacity of certain pathogens to infect immune-skilled humans has been found. Their ability to build resistance scares humans, and with those species it takes an hour to resolve. The findings of our bacterial isolates' antibiotic susceptibility showed that these species are well known to the antimicrobials tested and that they are evolving mechanisms that inhibit these antibiotics, which are completely compatible with Abdallah et al . A significant field of antibiotic science is currently the multiple resistant bacteria's search for new successful antibiotics against multi-drug pathogenic bacteria.

\section{ACKNOWLEDGEMENTS}

The authors strongly acknowledge Vinayaka mission research foundation (deemed to be university) and Vinayaka mission medical college, Karaikal for the facilities provided.

Conflict of Interest: Authors does not have any conflict of interest

\section{REFERENCES}

Abdallah, Nermeen Mahmoud Ahmed, et al. (2011) "Biofilm forming bacteria isolated from urinary tract infection, relation to catheterization and susceptibility to antibiotics." International Journal of Biotechnology and Molecular Biology Research 2.10: 172-178.

Beyene, Getenet, and Wondewosen Tsegaye (2011) "Bacterial uropathogens in urinary tract infection and antibiotic susceptibility pattern in jimma university specialized hospital, southwest ethiopia.” Ethiopian journal of health sciences 21.2: 141-146. 
Ganderton, L., et al. (1992) "Scanning electron microscopy of bacterial biofilms on indwelling bladder catheters.” European Journal of Clinical Microbiology and Infectious Diseases 11.9 : 789-796.

Holá, Veronika, Filip Ruzicka, and Marie Horka. "Microbial diversity in biofilm infections of the urinary tract with the use of sonication techniques." FEMS Immunology \& Medical Microbiology 59.3 (2010): 525528.

Hola, Veronika, Tereza Peroutkova, and Filip Ruzicka. "Virulence factors in Proteus bacteria from biofilm communities of catheter-associated urinary tract infections." FEMS Immunology \& Medical Microbiology 65.2 (2012): 343-349.

Lara-Isla, Alba, et al. "Urinary infections in patients with catheters in the upper urinary tract: microbiological study." Urologia internationalis 98.4 (2017): 442-448. Mandakhalikar, Kedar Diwakar, et al. "Extraction and quantification of biofilm bacteria: Method optimized for urinary catheters." Scientific reports 8.1 (2018): 1-9. Ogeer-Gyles, Jennifer, et al. "Evaluation of catheterassociated urinary tract infections and multi-drugresistant Escherichia coli isolates from the urine of dogs with indwelling urinary catheters." Journal of the
American Veterinary Medical Association 229.10 (2006): 1584-1590.

Pour, Nadia Kazemi, et al. "Biofilm formation by Acinetobacter baumannii strains isolated from urinary tract infection and urinary catheters." FEMS Immunology \& Medical Microbiology 62.3 (2011): 328338.

Sabir, Nargis, et al. "Bacterial biofilm-based catheterassociated urinary tract infections: Causative pathogens and antibiotic resistance." American journal of infection control 45.10 (2017): 1101-1105.

Wang, Xiaoda, et al. "Characteristics of biofilms from urinary tract catheters and presence of biofilm-related components in Escherichia coli." Current microbiology 60.6 (2010): 446-453.

$\mathrm{Xu}$, Yijuan, et al. "Culture-dependent and-independent investigations of microbial diversity on urinary catheters." Journal of clinical microbiology 50.12 (2012): 3901-3908.

Zahlane, Kawtar, Ahmed Tadlaoui Ouafi, and Mustapha Barakate. "The clinical and epidemiological risk factors of infections due to multi-drug resistant bacteria in an adult intensive care unit of University Hospital Center in Marrakesh-Morocco." Journal of infection and public health 13.4 (2020): 637-643. 